\title{
Over werken, niet werken, terugwerken en thuiswerken
}

\section{Terugblik online symposium Re-integratie werkt! van Universiteit Gent}

\section{Het online symposium Re-integratie werkt! ${ }^{1}$ van de Universiteit Gent op 29 april 2021 trok 400 Belgische deelnemers. Het dagprogramma opende met keynote- speaker professor Michiel Reneman ${ }^{2}$ van de Universiteit Groningen. Hij gaf zijn visie op Disability Management.}

\section{Katrien Mortelmans}

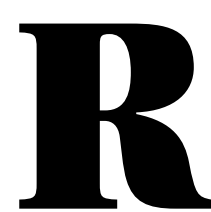

eneman startte met de heldere definitie van Disability Management zoals die in België door het Rijksinstituut voor Ziekte- en Invaliditeitsverzekering (RIZIV $\left.{ }^{3}\right)$ wordt gehanteerd. 'Disability Management is een methode gericht op jobbehoud of re-integratie, die aansluit bij het biopsychosociale denkkader. Centraal staan de individuele noden van de werknemer, de omstandigheden op de werkplaats en het wettelijk kader.' Daarna kwamen de hoofdrolspelers uit onderstaande casus aan het woord.

\section{Casus: Burn-out}

Op een dag ging het gewoon niet meer: Marc was al uitgeput na een kwartier werk. De diagnose luidde burn-out. Na wat omwegen kwam Marc terecht bij Els, een gecertificeerd Disability Managementprofessional ${ }^{4}$, oftewel een expert die arbeidsongeschikte personen naar werkhervatting begeleidt.

Els zette een werkhervattingstraject op en fungeerde als link tussen de direct leidinggevende van Marc, personeelsdienst, zorgverleners in burn-out en de adviserend arts van de mutualiteit (ziektekostenverzekering, red.), die de arbeids(on)geschiktheid evalueert.

Marc bouwde de werkhervatting gradueel op. Van 1 dag per week met beperkte taken zonder nachtwerk, naar voltijds en inhoudelijk quasi de totale opdracht. Quasi, want een deeltaakje, waar Marc zich onvoldoende competent in voelt, hetgeen stress veroorzaakt, is definitief uit zijn job-omschrijving geschrapt. Marathons kan Marc vooralsnog niet meer lopen, hij verzwaarde en is nog snel moe. Maar hij vindt gemoedsrust genietende van zijn sportende kinderen. 
'Disability Management-programma's zijn effectief en efficiënt, maar we weten niet of ze in elke context succesvol zijn. Dat dient verder onderzocht te worden. De omstandigheden in Vlaanderen en Wallonië kunnen verschillend zijn, de ene pathologie is de andere niet en patiënten uiten diverse noden', constateerde professor Reneman naderhand.

\section{Duurzaam thuiswerk}

Later die dag verzorgde professor Peter Vlerick ${ }^{5}$ een workshop over duurzaam thuiswerk.

'Is thuiswerken eigenlijk wel anders werken? Thuiswerken is het samenbrengen van privéen werkomgeving. We willen gelukkig zijn in ons privéleven en op ons werk en die twee interfereren soms. Voor sommigen leidt het tot conflicten en zelfs burn-out, anderen vinden het een absolute verrijking.' Zie Tabel 1 .

'Kortom, mensen reageren verschillend op remote work. Onderzoek pre-Covid-19, met experimenten in afstandswerk, leidde tot positieve resultaten, maar niet overal en niet bij iedereen. Sommige bedrijven betaalden werknemers zelfs een verhuispremie om dichter bij de firma te komen wonen en dus niet langer thuis te moeten werken', zo vulde Vlerick aan.

Bin Wang ${ }^{6}$ en anderen publiceerden over werken op afstand tijdens de Covid-pandemie en identificeerden vier belangrijke virtuele karakteristieken bij thuiswerkers (zie Figuur 1 op de volgende pagina):

- Verminderde sociale steun van onder anderen collega's en leidinggevenden.

- Toegenomen job-autonomie (bijvoorbeeld als het gaat om tijd, methode, tempo, etc.).

- Toegenomen monitoring door bijvoorbeeld het dagelijks moeten rapporteren aan werkgever of het moeten werken met een geactiveerde webcam.

- Toegenomen werkbelasting: thuiswerk impliceert niet noodzakelijk minder of gemakkelijkere werktaken.

Deze vier werkkarakteristieken kunnen volgens Wang op vier manieren een negatieve invloed hebben op de gezondheid en het welzijn van thuiswerkers. Deze kunnen immers energie vreten en werkstressoren vormen en zo aanleiding geven tot:

- Meer uitstelgedrag, inclusief voor nietwerkgerelateerde taken.

- Meer communicatieproblemen en misverstanden door bijvoorbeeld een te hoog aantal digitale berichten, onbeantwoorde mail, et cetera.

- Meer werk-thuis-conflict doordat het werk de keuken, living of slaapkamer binnenkomt. - Meer eenzaamheid of sociale isolatie.
Werk-familie-

interactie:

vier types.

\begin{tabular}{|l|l|l|}
\hline \multicolumn{1}{|c|}{ Direction } & \multicolumn{1}{|c|}{\begin{tabular}{c} 
Valence \\
\hline Work-to-family
\end{tabular}} & \multicolumn{1}{|c|}{ Negative } \\
\hline $\begin{array}{ll}\text { Work-to-family conflict } \\
\text { e.g. 'I am often late to pick up } \\
\text { my children from day care due } \\
\text { to my excessive work load and } \\
\text { deadlines.' }\end{array}$ & $\begin{array}{l}\text { Work-to-family enrichment } \\
\text { e.g. 'My current work is so } \\
\text { rewarding that even my spouse } \\
\text { often comments on my good } \\
\text { mood and effort spent on my }\end{array}$ \\
\hline Family-to-work & \begin{tabular}{l} 
family after a workday.' \\
\hline Family-to-work conflict \\
e.g. 'I find it often difficult to \\
concentrate on my clients' \\
sorrows due to problems with \\
my spouse.'
\end{tabular} & $\begin{array}{l}\text { Family-to-work enrichment } \\
\text { e.g. 'I have applied my skills and } \\
\text { experience from raising five kids } \\
\text { many times in my work as a } \\
\text { student counsellor.' }\end{array}$ \\
\hline
\end{tabular}


Bovenvermelde effecten van thuiswerk worden niet bij alle thuiswerkers in gelijke mate vastgesteld. Ook individuele kenmerken (denk aan persoonlijkheid) van thuiswerkers spelen een rol. Zo zijn mensen met een hoge mate van zelfdiscipline (bijvoorbeeld door sterke planning, georganiseerde aanpak) beter in staat om met hun (door thuiswerk) veranderde arbeidssituatie om te gaan. Zij ervaren minder werkstress.

\section{Hybride model}

Dit is de analyse tijdens de coronapandemie. Maar hoe gaat het erna? Waarschijnlijk wordt het een blended situatie, zo verduidelijkt Vlerick. 'Duurzaam thuiswerk' betekent alle voordelen van thuiswerk behouden en de mogelijke nadelen ervan voorkomen. En dus evolueren we naar een hybride model, oftewel distributed work. En daar is ongetwijfeld een rol weggelegd voor organisaties die zich buigen over preventie.

\section{Juiste mindset}

Tot slot noteerden we een tip voor thuiswerkers. In plaats van de vrijgekomen reistijd te incorporeren als werktijd, wordt geadviseerd om beide tijdslots te gebruiken om te wandelen, lopen of fietsen. Zo initieer je een mindset met een helder begin en afbakening van de thuiswerkdag.

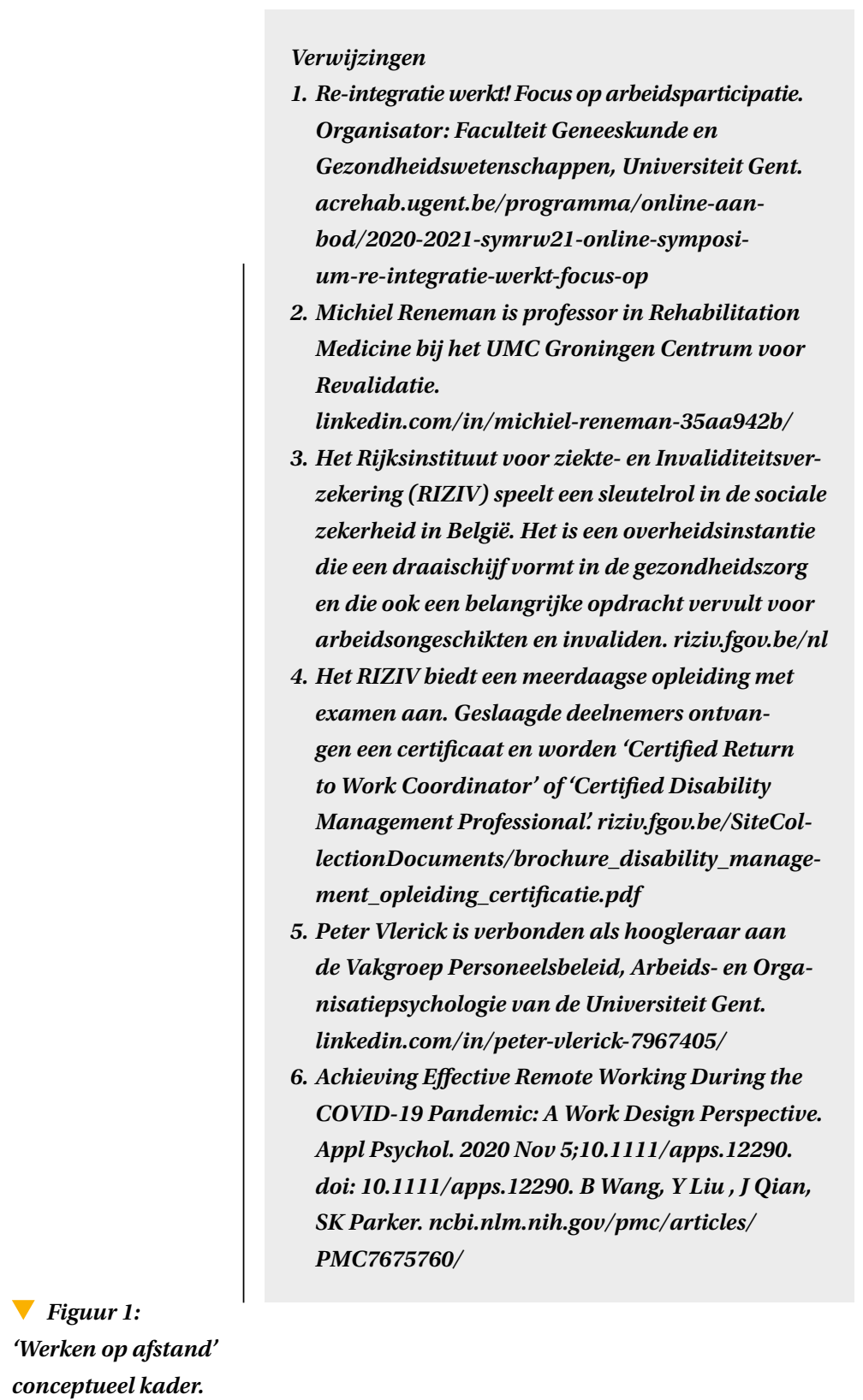

\section{Achieving effective remote working during the Covid-19 pandemic (Wang et al.,2020)}

\begin{tabular}{|c|c|c|}
\hline $\begin{array}{c}\text { Virtual work } \\
\text { characteristics }\end{array}$ & $\begin{array}{l}\text { Remote work } \\
\text { challenges }\end{array}$ & $\begin{array}{c}\text { Remote worker } \\
\text { outcomes }\end{array}$ \\
\hline $\begin{array}{l}\text { Social support } \\
\text { Job autonomy } \\
\text { Monitoring } \\
\text { Workload }\end{array}$ & $\begin{array}{l}\text { Procrastination } \\
\text { Ineffective } \\
\text { communication } \\
\text { Work-home interference } \\
\text { Loneliness }\end{array}$ & $\begin{array}{l}\text { Performance } \\
\text { Well-being }\end{array}$ \\
\hline \multicolumn{2}{|c|}{$\begin{array}{l}\text { Individual } \\
\text { factors }\end{array}$} & \\
\hline \multicolumn{2}{|c|}{ Self-discipline } & \\
\hline
\end{tabular}

